\title{
LAS ANTINOMIAS DE LA NACION CUBANA: LA AGENDA DE CUBA EN LA PERSPECTIVA DE IBEROAMERICA Y FRENTE A LOS EE.UU.
}

\author{
Rafael Hernandez (*)
}

En este ensayo nos proponemos analizar un grupo de problemas que afectan al cuadro de las relaciones interamericanas de Cuba, especialmente desde el vértice de su conflicto con los EE.UU. Aunque el propósito es discutir la inserción internacional de la isla, la explicacion de estos problemas requiere el examen de la economia, el sistema politico y la sociedad cubana misma. En otras palabras, que no nos detendremos solo en examinar la situación internacional en que estos se proyectan, sino sobre todo en analizar su evolución reciente y perspectivas a partir de la propia dinámica nacional.

Nos concentraremos en tratar de profundizar en torno a ciertas cuestiones claves, más bien que en intentar abarcar una descripción en detalle de los tópicos de la agenda interamericana de Cuba. Algunos problemas en que procuraremos ahondar son los siguientes: ¿En qué medida la posguerra fría ha modificado la situación real de Cuba y sus percepciones internacionales? ¿Cuál ha sido el efecto económico y político del derrumbe del socialismo europeo y del reforzamiento del bloqueo económico de los EE.UU.? ¿Qué factores afectan las relaciones entre los EE.UU. y Cuba y cuales son sus perspectivas? ¿Cuáles son los cambios actualmente en curso en la isla y con qué alternativas se enfrentan?

\section{BREVE INTRODUCCION HISTORICA}

La nación cubana emergió en medio de una sangrienta guerra anticolonial, que algunos han llamado la guerra de Vietnam del siglo XIX, por la trascendencia internacional, la intensidad y la radicalidad que la caracterizaron. La última de las posesiones españolas en las Américas, Cuba fue, al mismo tiempo, la más tardía de las guerras de independencia y el primer proyecto de revolución antimperialista de liberación nacional en el hemisferio. Jose Martí, el líder de esa guerra y el político cubano más universal, vivió los últimos trece años de su vida en los EE.UU., donde aprendió que la democracia norteamericana no era un modelo a seguir para la república cubana naciente, sino una amenaza. En efecto, incluso los grandes ideólogos demócratas en ese país, desde Thomas Jefferson hasta MacKinley, desde John Quincy Adams hasta John Kennedy, han pensado en Cuba como una parcela del territorio norteamericano, como la fruta madura de la geopolítica, que tendría que caer, por fuerza, en su patio.
La compenetración económica, política y cultural entre los EE.UU. y Cuba ha sido la más intensa entre el Norte y el Sur de nuestro hemisferio. Desde hace casi doscientos años, la nación cubana ha tenido a EE.UU. como su vecino más importante. La última joya de la corona española, Cuba fue el cruce de caminos del Nuevo Mundo, donde confluían las flotas americanas, las corrientes del pensamiento y la cultura universales. Por ello, en su historia como nación, Cuba jamás ha quedado aislada del cambio mundial y del progreso. A diferencia de los EE.UU., que durante más de un siglo estuvieron encerrados en su vasta provincia, la isla siempre ha estado abierta al mundo.

Cien años antes de que cesara la dominación política española en Cuba, ya los EE.UU. eran el socio comercial más importante de la que se convirtió después de la Revolución Haitiana en el mayor exportador de frutos tropicales del mundo. De EE.UU. vino la oleada de capital más intensa que conociera la economía cubana a principios del presente siglo, el impulso modernizador más potente, los patrones más sofisticados del capitalismo, los programas de salubridad y la pedagogía modernas. Cuba fue el primer país de la región en tener ferrocarril, teléfono, televisión. Las relaciones sociales del capitalismo neocolonial llegaron a los confines más remotos del país, abarcaron e integraron a una población que no estaba fragmentada en minorías étnicas ni dividida en regiones geográficas aisladas. La barbarie del capitalismo dependiente típico de una economía de plantación se combinó con la intensa dinámica del comercio a sólo noventa millas de los EE.UU.; la cultura cosmopolita y vanguardia intelectual con las más atroces dictaduras. La Habana era capital ultramoderna de un país que vivía sobre los hombros de cortadores de caña de azucar y a expensas del ejercito que disciplinaba. Los EE.UU. y sus aliados locales mandaban en la economía y en la política. No es extraño que la revolución pospuesta de Jose Martí antimperialista y social, siguiera inspirando a los cubanos, y en particular al movimiento que triunfara en 1959. Y que esa revolución se diera en Cuba, representando, en su momento, el pensamiento más avanzado de América Latina.

Es imposible, por consiguiente, entender la lucha por la independencia y la lucha por el progreso social como vectores separados en el contexto cubano. La defensa de la nación y el proyecto de democracia social juntos, se alimen- 
tan mutuamente, desde 1895 hasta hoy. Ambos afectan relaciones con nuestro principal vecino, los EE.UU.

\section{LA POLITICA DE LOS EE.UU. HACIA CUBA}

En 1959 y 1960, la política confrontacional de los EE.UU. contra la Revolución en Cuba contribuyó a acelerar el cambio político. Hoy esa política nuevamente constituye un factor influyente. ¿Cuál es su sentido?

La política norteamericana hacia Cuba se ha proyectado históricamente en cuatro niveles:

- La política doméstica

- La política hacia América Latina y el Tercer Mundo

- La política hacia la URSS

- Las relaciones bilaterales

A continuación examinaremos cada uno por separado de manera sumaria.

\section{Política interna.}

Cuba no es un tópico trascendental de la política doméstica de los EE.UU. Sobre Cuba se informa poco y de manera intermitente. La mayor parte de la información que aparece en la prensa de los EE.UU. sobre Cuba se refiere a la cuestión de los derechos humanos, la comunidad cubana o la debacle anunciada del socialismo en la isla. Esta posición secundaria compartida en general con el resto de América Latina, que sólo es tomada en cuenta como epifenómeno de ciertos temas cruciales - el comercio, la migración, el narcotráfico.

Si Cuba no es tan importante en el debate político interno como lo era en 1959-62, el contexto ideológico interno sí es determinante en el mantenimiento de la política hacia Cuba. La Revolución Cubana ha simbolizado el mal en el discurso ideológico norteamericano sobre todo ahora que la amenaza soviética literalmente ha desaparecido. En este contexto, los líderes cubanos han sido alineados con un elenco de actores internacionales negativos, entre Khomeini, Kadafi, Noriega, Sadam Hussein. Esto significa que no importa tanto lo que Cuba esté realmente haciendo o no. En virtud de esta operación ideológica, ha quedado presa de especulación y el debate político interno y de fenómenos como las campañas electorales.

En esta dinámica, algunos tienden a sobredimensionar el peso real del factor comunidad cubana, especialmente a partir del trato diferenciado que le han otorgado a su sector derechista las dos últimas administraciones republicanas. Este sector aprovecha un espacio creado por la hostilidad de la política exterior de EE.UU. hacia Cuba. En estas condiciones, la beligerancia y capacidad de influencia consentida al lobby neoconservador cubano-americano se han acrecentado. Ejemplos patentes de esta capacidad son los proyectos de Radio Martí y Tele Martí, en donde se les ha asignado un rol de primera fila. (1)

Sin embargo, en este mismo periodo la política norteamericana ha tomado decisiones como son el acuerdo migratorio de 1984/87 y la solución negociada al conflicto del suroeste de Africa en 1988 contrarias al interés declarado de este sector. Esto indicaría que, una vez que el interés nacional de EE.UU. se propusiera negociar con Cuba asunto determinado, esta política iría adelante, a pesar de la oposición del grupo de presión derechista cubano-americano. Y que si la política de los EE.UU. hacia Cuba no ha progresado, no se debe tanto a los dictados ese sector derechista, sino al hecho de que esa política ha estado y sigue estando dirigida a la liquidación del régimen cubano.

De hecho, la población cubana en EE.UU. tiene una dinamica interna que suele desconocerse por la mayoría de los políticos norteamericanos. La existencia de diversas corrientes políticas en su seno, y sobre todo la presencia de una mayoría silenciosa, que se beneficiaría de una relación más normal entre los dos países, aparecen nubladas por el discurso político dominante en la comunidad, de carácter conservador autoritario. (2)

Todos estos factores han incidido históricamente en la conformación de una percepción sobre Cuba en EE.UU. La política hacia América Latina y el Tercer Mundo.

Los ciclos en la política de los EE.UU. hacia Cuba se han caracterizado por coincidir con los ciclos en su política hacia América Latina. Cuando en 1974 empezó a cambiar la política norteamericana hacia América Latina, se identificaron como casos claves (test-cases) de la política norteamericana hacia la región los de Cuba y Panama. (3) En cambio, cuando en 1979 comenzaron a modificarse las percepciones norteamericanas sobre "la amenaza comunista” en Centroamérica, EE.UU. reaccionó como en 1959 (4). Parte de esta reacción fue el inicio de un nuevo ciclo de hostilidad hacia Cuba. (5)

Menos de un mes después de la pérdida de las elecciones por el FSLN en Nicaragua el 25 de febrero de 1990, los asesores militares cubanos se retiraron de ese país. El proceso de negociación en El Salvador, entre el FMLN y el gobierno de ARENA, ha avanzado hasta el punto de lograr un acuerdo pacífico en enero de 1992. El peso que alguna vez pudo tener la ayuda cubana a la guerrilla literalmente ha desaparecido.

(1) Cfr. Jose R. Cabañas, “Radio Martí: una nueva agresión”, en Cuadernos de Nuestra América, No. 1, enero-julio de 1984, p. 174-204; y Arnaldo Coro, "Tele Martí: una nueva escalada", en Cuadernos de Nuestra America; $\mathrm{N}^{\circ}$. 12, enero-junio de 1989, p. 143-158.

(2) Para una discusión vease, de Rafael Hernandez: "Certain Fallacies in Relation to the Cuban Community in the United States" en Joseph Tulchin \& Rafael Hernandez (ed.), The United States and Cuba: Will the Cold War End in the Caribbean?, The Wison Center, Washington, 1991; y "Sobre las relaciones con la comunidad cubana", en Cuadernos de Nuestra América, No 17, julio-diciembre, 1991.

(3) Este proceso se inició bajo la administración Ford y estuvo impulsado por el secretario de Estado Henry Kissinger. De lado de los demócratas, véanse los Informes Linowitz de 1974 y 1977 en Serie Documentos, No. 1, CEA, abril de 1980. La Comision Linowitz ha seguido existiendo bajo el nombre de Diálogo Interamericano. Diecisiete años despues, el Diálogo Interamericano podría volver a identificar a estos casos -y en particular a Cuba- como claves de la política latinoamericana de EE.UU.

(4) Vease Robert Pastor, Condemned to Repetition, Princeton University Press, 1987.

(5) Para una discusion detallada vease Rafael Hernández, "La lógica de la frontera en las relaciones EE.UU.-Cuba", en Cuadernos de Nuestra América, № 7, enero-junio de 1987. 
Por otro lado, en noviembre de 1988, los gobiernos de Angola y Cuba de un lado, y de la República de Sudáfrica del otro, con la participación activa de los EE.UU. y de las Naciones Unidas alcanzaron un acuerdo. El 25 de mayo de 1991 se anunció la conclusión del retiro de tropas de Angola. Hace más de tres años que los gobiernos de Etiopía y Cuba acordaron y ejecutaron la retirada total de tropas cubanas de suelo etíope. Cuba y Somalia, antiguos enemigos, han restablecido relaciones diplomáticas.

Puede afirmarse que no existe hoy en día ninguna colaboración militar cubana en el Tercer Mundo que pueda esgrimirse por EE.UU. como preocupación de seguridad internacional es decir, como pretexto para mantener la tensión con Cuba.

\section{La política hacia la URSS}

Cuando los EE.UU. y la URSS se sentaron a enterrar por primera vez la guerra fría, en 1971-72, inaugurando el periodo conocido como la detente, Cuba no fue un tema de negociación. En cambio, el proceso de la nueva relación soviético-norteamericana si ha conllevado un conjunto de presiones de EE.UU. para que la URSS reduzca su relación económica y militar, y tire por la borda una política de treinta años en sus relaciones con el Tercer Mundo. Esta visión norteamericana - una URSS debilitada, como factor capaz de modificar la conducta de Cuba- es central en el actual rumbo de la política de EE.UU. hacia la isla. (6)

Desde la cumbre de Malta, Cuba apareció en la agenda soviético-norteamericana cada vez más a menudo. EE.UU. se limitó a una actitud de chantaje, condicionando sus favores económicos a la antigua URSS a una reducción de la colaboración con Cuba.

La evolución de las relaciones EE.UU.-URSS a lo largo de 1990-92, y sobre todo el desmembramiento de la antigua la URSS han disipado la cuestión de la "amenaza soviética" en Cuba. Sin embargo, ni siquiera el anunciado retiro de la brigada soviética remanente de las tropas de 1962 en la isla logran hacer desaparecer totalmente este punto.(7)

En definitiva, así como la presencia soviética en Cuba no estuvo en el origen del conflicto, tampoco su ausencia lo resolverá. El conflicto de intereses nacionales opuestos a lo largo de doscientos años emerge hoy de nuevo como el problema central entre los dos países.

\section{Las relaciones bilaterales.}

En términos relativos, los problemas de la agenda bilateral parecen tener una solución viable por la negociación. Los principales son los siguientes:

- El bloqueo / las indemnizaciones a las empresas norteamericanas nacionalizadas.
- Las incompatibilidades de la radiodifusión (problemas relacionados con la contigüidad de los espectros radioeléctricos de ambos países y con la reciprocidad en las transmisiones mutuas); y todo lo relacionado con el derecho a transmitir hacia el otro país.

- La migración.

- La base naval de Guantánamo.

En general, se considera que todos podrían negociarse si existiera la voluntad política. (8)

En principio, el progreso en el área de mayor sensibilidad para las relaciones cubano-norteamericanas -los problemas de la agenda internacional- debería haber implicado una sustancial mejoría entre los dos países. Sin embargo, la objeción principal al régimen cubano ha dejado de ser "la exportación de la revolución" o "la presencia soviética en Cuba". En particular desde fines de 1989, Cuba ha sido vista a través de los lentes eurorientales. Algunos esperan que Cuba siga los caminos ya vistos en el campo socialista. Estos escenarios se basan en la presunción de que no hay salida a la situación económica, una vez que la URSS se ha ido desintegrando, y que la desaparición del socialismo en Europa ha borrado toda viabilidad política a cualquier modelo socialista en el mundo.

Segun esta lógica, EE.UU. debe mantener su política de bloqueo y aislamiento, hasta lograr que la crisis económica y la inestabilidad hagan la tarea de derrocar el socialismo en Cuba. De cierta manera, es como si el reloj se hubiera retrotraído a 1960 aunque con un contexto internacional muy diferente. Como entonces, la verdadera esencia del conflicto de intereses no radica en las relaciones de Cuba con la URSS o los movimientos revolucionarios, sino en el régimen cubano mismo.

En efecto, según afirmó el presidente Bush el 27 de febrero de 1992: "si Cuba celebra elecciones totalmente libres y justas bajo supervisión internacional, y respeta los derechos humanos las relaciones mejorarán” (9). Esto se traduce concretamente en los siguientes términos. Primero: Cuba debe establecer una democracia certificada por elecciones observadas y calificadas "internacionalmente". Es decir, no basta con que los cubanos quieran implementar reformas en su sistema electoral, para hacerlo más participativo y eficaz; sino se trata de que una institución "internacional" como Amnesty International o el Centro Carter debe venir a juzgar el cambio que se está dando en el propio pueblo cubano. Segundo: Cuba debe abandonar su "modelo económico cerrado", ya que se ha probado el fracaso del "modelo estatista" en América Latina y que los "gobiernos centrales fuertes" son cosa del pasado. O sea, que no es suficiente con que se rectifique el rumbo de la economía cubana y se abra la colaboración con el capital

\footnotetext{
(6) Statement of Bernard Aronson, Assistant 8ecretary of State for Inter-American Affairs, before the Subcommittee on Western Hemisphere Affairs, House of Representatives, June 20, 1991, p. 12.

(7) La reducción del suministro de armas sovieticas a Cuba se anunció varios meses antes que la brigada. Vease Fidel Castro, "Discurso en el XXX Aniversario de la Victoria de Playa Girón”, 19 de abril de 1991, en Granma, Suplemento especial, 20 de abril, p. 4

(8) De hecho, la cuestión migratoria fue objeto de un acuerdo con la administración Reagan en 1984 y 1987, lo que ha permitido una relativa normalización de este problema, aunque en la práctica se mantiene todavía cargado políticamente.

(9) George Bush, "A Challenge to Hold Free Elections", The Miami Herald, 27 de febrero de 1992
} 
extranjero, sino que las reformas deben tener un corte neoliberal radical, borrando el papel del Estado en la economía. (10)

Este proceso, según reconoce el propio Aronson, permitiría "un tránsito pacífico, a través de la institucionalidad democrática, hacia un gobierno sucesor". En resumen, las elecciones democráticas, los derechos humanos y la economía de mercado son elementos de un plan norteamericano para cambiar pacíficamente el régimen político y social de Cuba. (11)

\section{¿Puede cambiar la política de los EE.UU. hacia Cuba?}

Incluso vista desde el ángulo norteamericano, esta política resulta contradictoria con algunos intereses y motivaciones que EE.UU. declara tener hacia Cuba. Hagamos un esfuerzo por colocarnos en los zapatos norteamericanos, y veremos que existen al menos diez razones para considerarla así.

1. La actual política de EE.UU. contra Cuba no refleja su supuesta preocupación acerca de la preservación de los derechos humanos en la isla, ni de los intereses del pueblo cubano. El mantenimiento de una estrategia que impide el acceso de alimentos y medicinas a la población de Cuba resulta poco creíble como posición humanitaria. La política del embargo obstaculiza, por ejemplo, el establecimiento de líneas modernas de comunicación telefónica entre los dos países. Esto no afecta especialmente al gobierno de Cuba, pero sí a los millones de personas que tratan infructuosamente de hablar con sus parientes con ambos países todos los días. Esta política solo logra reforzar el papel de los EE.UU. como verdugo del pueblo cubano.

2. Toda la presión que EE.UU. coloca sobre Cuba reaviva el fuego de la fortaleza sitiada en la isla. Objetivamente, las dificultades económicas y las presiones externas desfavorecen el proceso de cambios, en la medida en que afectan el espacio de debate interno, limitan el proceso de descentralización y contribuyen a darle mayor peso a la defensa. El efecto psicológico del asedio no es precisamente ampliar las libertades.

3. El mantenimiento de la política hacia Cuba refleja la vieja doctrina del "gran garrote" en el Caribe. La razón de ser de esa política no se sostiene en el rechazo ideológico al socialismo, pues socialismo hay en China o Vietnam, con los cuales EE.UU. ha ido logrando un entendimiento. La gran diferencia entre Cuba y estos otros países es que ninguno de estos está situado en la zona de influencia norteamericana por excelencia. Además, para otros países caribeños esta lección refuerza los ecos de Granada y Panamá.

4. La política actual está proyectando que no quiere alcanzar un arreglo con Cuba, sino ponerla de rodillas. Esa política ignora los progresos habidos en la agenda internacional del conflicto con Cuba -Angola, Centroamérica, la
URSS-, poniendo como nueva condición para normalizar relaciones que se produzcan cambios en la política interna cubana. Esto encierra una amarga lección para los cubanos: EE.UU. no quiere poner fin a una situación anómala y peligrosa para la paz y la seguridad en el Caribe, sino dar un castigo ejemplar a una pequeña nación que desafió su dominio en la región.

5. Posponer un diálogo con Cuba en espera de que el socialismo se caiga, no promete un cambio, sino una variante de la misma relación conflictiva existente hasta ahora. En efecto, supongamos que EE.UU. espera dos o tres años para entablar un diálogo con Cuba. ¿Habrá abandonado entonces su intención de intervenir en los asuntos internos de la isla? El legado de desconfianza entre los dos países estará intacto dentro de dos o tres años. Por otra parte, la política de forzar cambios en Cuba le entrega hoy al régimen socialista cubano un argumento para asumir que no existen reglas del juego que deba respetar en las relaciones con los EE.UU.

6. Mientras el socialismo no se cae, Cuba estrechará sus relaciones económicas y políticas con otros países, incluídos los de América Latina y el Caribe. Este espacio de encuentro con Cuba será un plano hemisférico del cual EE.UU. seguirá ausente, lo cual de por si no beneficia sus intereses, ni los de su comunidad de negocios.

7. EE.UU. puede perder hoy una oportunidad económica y política única para un cambio de imagen en Cuba. Al excluir la apertura de relaciones normales, reforzará la preocupación que tienen hoy muchos cubanos acerca de que las relaciones con el Norte podrían ser buenas para la economía pero malas para la política; es decir, beneficiosas para el desarrollo económico, pero negativas para el clima político interno y la independencia nacional. Una vez que el momento crítico para la economía hubiera pasado, la posibilidad de un diálogo con los norteamericanos podría resultar todavía menos deseable para los que así piensan en la isla.

8. No hay seguridad de que un nuevo foco de crisis no surgirá en las relaciones bilaterales. Algunos problemas, como la cuestión de la migración, no van a recibir un tratamiento plenamente racional hasta que las relaciones entre ambos países se normalicen. Las probabilidades de que ocurra una crisis aumentan en la misma medida en que las presiones externas sobre la isla se incrementen. Los próximos años no están exentos de este peligro.

9. EE.UU. no tiene alternativa con Cuba. En 33 años, lo ha usado todo, salvo los marines. No dispone de nuevos instrumentos, ni puede poner mucha más presión que la que ya ha puesto. Puede no facilitar el rebasamiento de la situación económica cubana. Pero no puede impedir que Cuba desarrolle recursos de supervivencia y alternativas económicas. Difícilmente podrá aislar a Cuba en el hemisferio, como en la segunda mitad de los 60 de manera que no podrá garantizar ahogarla económicamente.

10) B. Aronson, ob. cit., p. 1,2 y 4-5.

(11) El plan de Bush especifica el mantenimiento de Radio y Tele Martí, las presiones sobre otros países para aislar a Cuba en la ONU (especialmente en torno al tema de derechos humanos) y para entorpecer las relaciones comerciales externas de la isla, prometiendo "una vasta gama de asistencia y ayuda a los cubanos a restaurar su tradiciones democráticas" una vez que Fidel Castro deje el poder. (Ver Bush, loc. cit.). 
10. La pretensión de que la política hacia Cuba responde a la comunidad cubano-americana no es consistente con la realidad. Según recientes encuestas, un sector de la comunidad piensa que EE.UU. debería lanzar una invasión contra la isla. Paradójicamente, esta misma opinión pública considera que EE.UU. debería establecer negociaciones con Cuba destinadas a traer más familiares y a mejorar el servicio telefónico. Obviamente, la política norteamericana sigue menos los deseos, constructivos y destructivos, de la comunidad cubana de lo que se pretende.

\section{LA SITUACION CUBANA}

Viéndolo en términos puramente económicos, la onda expansiva del derrumbe del muro de Berlin ha sido equivalente a un ataque externo para la sociedad cubana.

Del bloque socialista -especialmente de la URSS y la RDA- llegaban a Cuba piezas de repuesto, petróleo, insumos para la producción de alimentos, a cambio de azúcar, cítricos, níquel cubano. En medio de la crisis económica que sacudió a América Latina a partir de los primeros años 80, Cuba se vio impelida a concentrar aún más sus relaciones económicas con la antigua URSS y Europa Oriental. En 1989, las relaciones comerciales de Cuba con el bloque socialista habían llegado al $80 \%$. En apenas dos años se perdieron para Cuba los términos de intercambio acordados, cayeron verticalmente los suministros, se restringieron los créditos. Segmentos de mercado importantes desaparecieron virtualmente del día a la noche.

La brusca reducción de suministros como el petróleo y la harina de trigo, procedentes de la URSS, creó serios problemas de transporte y de escasez de alimentos que se transmitieron inmediatamente al nivel de vida de la población cubana. Súbitamente privada de sus socios comerciales y financieros principales, con una baja reserva de dólares (ya que la mayor parte de su comercio se realizaba en rublos) Cuba se ha visto en la difícil situación de haber perdido, al mismo tiempo que sus mercados de exportación, las fuentes de abastecimiento y de crédito, de manera que su capacidad de compra se ha visto doblemente impedida. Por otra parte, sectores claves de la economía, como el níquel o los cítricos, se quedaron sin capital para funcionar adecuadamente. En 1991, el decrecimiento de la economía nacional alcanzó cifras récord. Por primera vez desde 1959, el desempleo ha sobrepasado el $5 \%$. El número de fábricas que han tenido que parar o reducir su producción por falta de energía o de insumos equivaldría al efecto de un severo ataque contra el parque productivo de la isla. Ese ataque equivale al $60 \%$ de la capacidad instalada de la industria cubana.

Bajo estas condiciones extremadamente críticas, el tejido social cubano está pasando una prueba de resistencia similar a la que los ingenieros someten a los materiales de construcción. Seria pueril tratar de subestimar el shock social de esta onda expansiva sobre la vida del país. El consenso político no es indiferente al agravamiento acelerado de las condiciones de vida. Después de conocer un ciclo de crecimiento sostenido de cerca de veinte años, el pueblo cubano no es invulnerable a la abrupta caída de su nivel de vida.
El liderazgo político tiene hoy que gobernar un país que no lo sigue como en 1962, de manera prácticamente unánime. Gobernar solo con una mayoría, y en medio del descontento, las formidables dificultades de repartir la escasez, la ineficaz comunicación ideológica con el mundo exterior y las bravatas de los EE.UU. no es una tarea suave. Pero el principal desafío del gobierno cubano no es siquiera mantenerse en el poder mientras logra descabezar a esta hidra. A mi juicio, lo que está en juego para la dirección cubana no es la probabilidad de que la restauración contrarrevolucionaria prevalezca -sin subestimar su actividad reciente-, sino la amenaza de que la depresión económica ponga un asedio a su política social y, sobre todo, a la credibilidad del socialismo como solución a los problemas del país. En otras palabras, la posibilidad de una sociedad con igualdad y justicia social.

Aunque los críticos parámetros del proceso cubano pueden deparar situaciones muy duras en los próximos meses, no cabe duda de que ya el sistema ha demostrado una excepcional capacidad de asimilación. Difícilmente una caída tan brutal en los niveles de crecimiento económico en cualquier otro país de América Latina habría tenido una amortiguación comparable. La estabilidad del sistema político, en medio de la crisis económica, ha revelado una capacidad de gobierno envidiable para cualquier régimen del hemisferio. La inexistencia de estallidos sociales o de síntomas serios de ingobernabilidad no son sólo señales del control ejercido por el aparato del Estado, sino evidencias del grado de consenso y, especialmente, resultados de una política que reparte equitativamente el costo social del reajuste de una manera que no puede lograrse en otros países de la región.

Naturalmente, a la población de Cuba no le sirve de mucho consuelo para enfrentar la sobrecarga de la vida cotidiana el saber que en América Latina hay 200 millones de pobres. Pero si queremos entender la naturaleza de los problemas cubanos, y especialmente, la posibilidad de sus salidas, es necesario reflexionar sobre el escenario natural del país real -y posible- que es Cuba.

Si el socialismo de Cuba, asediado por una prensa internacional poco amistosa, es percibido como un objeto anacrónico por amplios sectores de la opinión pública latinoamericana, paradójicamente, la tarea en que se encuentra enfrascado tiene una central actualidad iberoamericana. En Cuba se prueba hoy, en las más duras condiciones de ingeniería social, si los Estados latinoamericanos pueden hacer algo por enfrentar el impacto demoledor de las fuerzas del mercado trasnacional sobre la integridad y unidad de la nación. En efecto, el problema cardinal de cómo el Estado protege a las diferentes partes de la nación mientras el mercado trasnacionalizado hace crecer el producto económico atormenta a las democracias latinoamericanas de los 90. Sin confianza electoral, sin partidos con una base social sustancial, incapaces de controlar a sus militares, reventadas por la crisis económica y la marginación de casi la mitad de su población, las democracias capitalistas latinoamericanas de la era del neoliberalismo no representan un modelo razonable para los problemas de Cuba. Establecer un régimen 
político y ecónomico que permita el crecimiento a costa de dejar fuera del mercado al $40 \%$ de la población es una opción que puede hacerse en países donde una parte considerable de la gente queda normalmente fuera del mercado, siempre contando con la valiosa contribución de un aparato de coacción apropiado. En Cuba, simplemente, esta alternativa no es viable, a menos que se quiera provocar una guerra civil de proporciones incalculables.

Esto significa que ningun liderazgo cubano realista, asumiendo conscientemente a la sociedad civil que tiene debajo, podría instrumentar la alternativa capitalista que tendría a su derredor en América Latina, sin hacerse responsable de una ruptura fundamental en el pacto social. El pueblo cubano, especialmente los sectores de menores ingresos, los trabajadores más humildes, la poblacion rural, los negros, los ancianos, cuyos niveles de vida han crecido como resultado de la redistribución del ingreso, cuyas atribuciones sociales son sostenidas por el régimen socialista, y cuya imagen en la cultura política actual es la del ciudadano con derechos efectivos, se resistiría a aceptar una fórmula que lo privara de facto de estos beneficios. El mismo ciudadano que hoy protesta por la situación económica, critica la ineficiencia burocrática y se manifiesta de manera bastante cruda hacia las consignas que no reflejan su modo de pensar, se rebelaría mañana contra un cambio en el sistema político que lo despojara de estos beneficios, no importa si el origen de estos cambios proviniera de una decisión del gobierno, de la imposición externa o incluso de una consulta plebiscitaria. Por cierto, que tampoco en Iberoamérica se ha sometido a consulta plebiscitaria los cambios económicos neoliberales, ni la privatización del sector público, ni las políticas de ajuste.

Si en otros momentos las políticas revolucionarias han tenido como metas expediciones de liberación africanas o latinoamericanas, hoy es obvio que el foco se encuentra en la grave situación económica del país. Igual que a partir de 1970, cuando la población reclamó una política económica y una administración más eficientes, la dirección de la Revolución está reflejando hoy, a nivel de sus políticas concretas, la urgencia de las trasformaciones económicas necesarias para adaptarse a un mundo sin Unión Sovietica ni países socialistas europeos.

¿Qué importancia tiene ésto para la democracia? Pensar que estas medidas de emergencia económica van a ser decididas democráticamente es un buen deseo, en el mejor de los casos. Las medidas descentralizadoras sólo podrían partir, como lo han estado haciendo en relación con la asociación al capital extranjero, del poder central. En medio de la crisis económica, las presiones externas y el enconamiento ideológico, se reaviva el fuego de la fortaleza sitiada. Y en las fortalezas sitiadas no florecen los estilos democráticos. A pesar de eso, la demanda popular que precedió al IV Congreso del Partido, posiblemente el proceso de debate y análisis crítico más profundo y amplio que haya conocido la sociedad socialista cubana, se expresó claramente a favor de la descentralización, la eficiencia económica, la mayor participación popular en las decisio- nes, la democratización de las instituciones políticas del país (en primer lugar, el propio Partido Comunista y la Asamblea Nacional), la eficacia de los mecanismos de representación política (especialmente las elecciones), la lucha contra la discriminación de los creyentes religiosos, y las formas de promover una mayor participación de jóvenes, mujeres y negros en los organismos de dirección del país. El respaldo popular al liderazgo en este proceso de reformas -o rectificaciones al socialismo, como se dice en Cuba- fue palpable a fines de 1990, cuando se discutió el Llamamiento al IV Congreso.

Desafortunadamente, estos temas obligados de la conversación diaria y reflejados en cierta medida en la prensa cubana de la época, sufrieron un desplazamiento fundamental con el agravamiento de las condiciones económicas. Si los cubanos de 1990 discutíamos sobre todo de cambios económicos, políticos e ideológicos, como los que se indican arriba, los de 1992 le dedicamos la mayor parte de nuestro tiempo a enfrentar las dificultades de la vida cotidiana que se han mencionado.

Ello no significa, sin embargo, que se pueda relegar o posponer la solución de los problemas del sistema político. El hecho de que la mayor parte del esfuerzo esté consagrado a las dificultades del abastecimiento de alimentos y artículos de primera necesidad, no implica que se haya renunciado a la restructuración necesaria de las instituciones y a las rectificaciones del sistema.

\section{EL CAMINO (REALISTA) A LA AMPLIACION DE LA DEMOCRACIA}

El IV Congreso del Partido no fue la panacea de los problemas que aquejan a Cuba, ni creo que la mayoría de la población esperara realmente que fuera así. Una de sus resoluciones más importantes, sin embargo, fue precisamente la relacionada con las modificaciones del poder popular y de la constitución (12). Los problemas que estas modificaciones constitucionales se proponen abordar -según está previsto para el próximo periodo de sesiones de la Asamblea Nacional en el mes de julio- reflejan centralmente la naturaleza del debate político existente en el país desde 1990, y constituye una agenda crítica de cuestiones y enfoques de especial significación para entender la mente política nacional. Una de las discusiones más importantes es la que se refiere a una nueva ley electoral. La Asamblea Nacional debe enfrentar estas dos tareas estratégicas, la reforma constitucional y la nueva ley electoral, en el transcurso del presente año.

Se espera que la Asamblea Nacional discuta y apruebe propuestas de modificación al $44 \%$ de sus artículos, así como la incorporación y derogación de otros. Se intenta despojar a la actual constitución de un conjunto de detalles reglamentarios que han impedido su aplicación creadora. En buena medida, se trata de acercarla más al pensamiento político y jurídico cubano, y de desembarazarla de muchos elementos copiados de cartas de Europa Oriental y la URSS. 
La reforma constitucional deberá enfrentar un grupo de problemas de trascendencia para la organización económica y política del país, y de profunda repercusión en el terreno ideológico. Uno de estos es la cuestión de la propiedad. Esta se reconoce a través de múltiples formas taxativas, que excluyen la propiedad privada y la posibilidad de inversiones extranjeras lo que ha provocado que la propia constitución entre en contradicción con regulaciones legales aprobadas posteriormente, como el Decreto Ley 50 de 1982, y el propio Código Civil promulgado en 1988. Es necesario una reconceptualización de este tema, no sólo para que pueda ser reconocida la propiedad a extranjeros, según las leyes cubanas, sino para que la cuestión de la propiedad en general reciba un tratamiento más amplio, y que el Estado pueda legislar sobre la materia con una base jurídica sólida y a la vez consistente con la política socialista.

Un ejemplo de cuestión ideológica en torno a la constitución es el problema del carácter laico del Estado cubano y la eliminación de todo vestigio de discriminación contra las prácticas religiosas. Si bien el IV Congreso del PCC avaló el levantamiento de las restricciones a los creyentes para ingresar al Partido, se ha debatido además la necesidad de que el ateísmo deje de ser una doctrina estatal.

La cuestión política más importante debe ser la revisión del proceso electoral y todo lo relacionado con el sistema del poder popular. Este es un elemento clave para toda la discusión sobre la participación política. El eje rector de estos cambios debe ser la elevación del contenido democrático del proceso, buscando que los mecanismos electorales permitan a los niveles locales enviar a sus representantes directos al nivel nacional.

La Asamblea Nacional ha recibido numerosas críticas. Posiblemente la principal sea su falta de peso efectivo en el tratamiento de los grandes problemas nacionales. En torno a esta crítica fundamental aparece el problema de que la Asamblea Nacional esté integrada por los diputados más capaces de representar políticamente a sus electores. Y de que éstos puedan desempeñar su rol como diputados profesionalmente, en lugar de ser, entre otras funciones, diputados, como ocurre ahora. Así como la necesidad de que la Asamblea tenga capacidad real de fiscalización crítica y control sobre los órganos administrativos del Estado.

Muchos de estos tópicos dan lugar a un intenso debate. Una cuestión polémica típica es la siguiente: ¿Debe existir algún sistema de cuotas que respalde legalmente la presencia proporcional de sectores políticamente en desventaja objetiva en cuanto a su acceso a posiciones de poder, como ocurre con las mujeres, los jóvenes o los negros? ¿o debe dejarse que la voluntad popular se exprese directamente, sin ningún tipo de orientación o regulación, de manera que se preserve la libertad total del voto, aunque ésto pueda dar lugar a desproporciones en cuanto a la representatividad social? ¿Cómo se pueden alcanzar ambos objetivos?

Evidentemente, uno de los problemas más complejos es el de promover el pluralismo. Pluralismo no equivale a pluripartidismo. En Cuba había en 1958 catorce partidos y muy poco pluralismo. El principio que gobierna el sistema político cubano consiste en que ningún partido -sin excluir, desde luego, al PCC- puede nominar sandidatos o llevar a cabo campañas electorales. Sin embargo, este principio de democracia directa debe ser realizado plenamente en la práctica a todos los niveles. Se trata de que la ley electoral permita dar cabida a todos los ciudadanos, independientemente de su credo filosófico, su fe o sus ideas políticas. Es decir, que el espacio democrático quede definido de manera tal que, si una parte de los electores decidieran votar por un candidato representante de un sector social o políticamente minoritario, existan las garantías procesales para que éste pueda realmente presentarse como candidato y ser elegido, si cuenta con la mayoría, hasta el nivel nacional.

Estrechamente relacionado con lo anterior está la cuestión de las llamadas organizaciones de masa y sociales -los sindicatos, las asociaciones profesionales, las federaciones femeninas, campesina, estudiantil, las organizaciones comunales- cuya revitalización es esencial en el proceso de democratización cubana. El papel de estas diferentes organizaciones y de los sectores que representan, están ligados a una dinámica propia de la sociedad civil, que requiere ser reconocida plenamente -y no como el de ejecutoras de funciones estatales. Obviamente, el rol de estas organizaciones en la presentación de candidatos a la Asamblea Nacional es sólo un aspecto, si bien de cardinal importancia, de su función dentro del sistema político cubano.

Problemas tan arduos como éstos ocupan al Estado y a la sociedad cubana en estos tiempos difíciles. Resulta notable que, a pesar del impacto de la crisis económica sobre la vida nacional, sigan estando priorizados y, de hecho, se les haya podido seguir prestando atención. Esta es una clara señal de la voluntad política con que se desarrollan los cambios.

\section{CONSIDERACION FINAL}

Existen todas las condiciones internacionales y suficientes condiciones internas para un cambio de la inserción de Cuba en el contexto iberoamericano, si en éste prevalece el pluralismo y la no injerencia en los asuntos internos de los distintos países. Los factores internos e internacionales presentes en el contexto actual constituyen seguramente la combinación más compleja que haya existido para Cuba desde 1962-63. Si la historia de los primeros años de la Revolución pareciera volver a repetirse en algunos aspectos, la coyuntura internacional puede permitir hoy cursos históricos que entonces no fueron posibles.

La proyección de la política norteamericana no parece moverse aún en una dirección que facilite este proceso. Por el contrario, lo que tiende a configurarse como política hacia Cuba se caracteriza por los siguientes elementos:

- Aumentar las presiones en el contexto internacional y regional, especialmente en el terreno ideológico, haciendo uso de variadas formas de intervencionismo, incluídas las que pueden generarse a través de los organismos internacionales.

- Seguir presionando sobre la antigua URSS para que ésta acelere la reducción de sus relaciones con Cuba, con vistas a lograr a corto plazo un debilitamiento económico y militar. 
- Conducir una política de dos pistas: mantener la presión y la coacción combinada con la operación de recursos diplomáticos a fin de producir una respuesta flexible a la esperada evolución de la situación interna.

Para muchos en el mundo de hoy el socialismo no es más que una utopía romántica del siglo XIX. Para Cuba es algo más que una preferencia filosófica o una filiación doctrinal.
Aceptar la "realpolitik" y el "nonsense" del socialismo equivale a admitir la irremisible dominación de los EE.UU. sobre la vida económica, política, ideológica y cultural del país. Y ésta no es una definición abstracta, sino una alternativa histórica concreta, que puede determinar el futuro de la nación.

\section{RESUMEN}

En este artículo, el autor analiza las relaciones entre EEUU. y Cuba en la actualidad y sus perspectivas. Para ésto, pasa revista a algunas de las facturas que son presentadas para explicar la política de bloqueo de EEUU. a Cuba, concretamente la alianza de Cuba con la Unión Soviética y la ayuda de aquélla a regímenes antiamericanos. El autor sostiene que esas facturas no son las causas principales de la política americana ya que ésta tiene una lógica propia en función de controlar una Cuba que, desde siempre, ha sido un objetivo geopolítico de EE.UU. Por último, el autor analiza las perpectivas de transformaciones internas del régimen cubano como respuesta a la crisis actual.

\section{ABSTRACT}

The current relations between United States and Cuba are analyzed in this work. It shows some factors that explain the USA blockade to Cuba; specifically the Soviet Union - Cuba alliance and the help of the Soviets to the anti- American political regimes. The author believes that such factors are not the main causes of the American foreing policy because this policy has its own logic: to control Cuba which has always been a USA geopolitics objective. Finally, he analizes the perspectives of the international transformations of Cuban political system. as response to the present crisis. 